\title{
Carbonization of solid uranyl-ascorbate gel as an indirect step of uranium carbide synthesis
}

\author{
Marcin Brykala, \\ Marcin Rogowski, \\ Tadeusz Olczak
}

\begin{abstract}
The studies of the synthesis of uranium carbide from uranyl-ascorbate gels using the complex sol-gel process (CSGP) have been carried out. The synthesis of uranyl-ascorbate mixture as liquid sol from uranium trioxide and ascorbic acid and solid gel by extraction of water from sol were carefully examined. Ascorbic acid was used as a complexing agent in complex sol-gel process and as a carbon source. The crucial step to obtain final uranium carbides from the aforementioned substrates is the carbonization process. The thermal behavior of ascorbic acid and uranyl-ascorbate gels in a nitrogen atmosphere in the temperature range of $25-900^{\circ} \mathrm{C}$ were investigated using TG-DTG. Furthermore, the products of the carbonization of uranyl-ascorbate gels in nitrogen, argon and vacuum atmosphere were identified by X-ray diffraction. TG-DTG was used also as a method for determining of carbon residues in the samples.
\end{abstract}

Key words: carbonization $\bullet$ complex sol-gel process (CSGP) $\bullet$ uranium carbide $\bullet$ uranyl-ascorbate complex

M. Brykala, M. Rogowski ${ }^{\bowtie}$, T. Olczak

Centre for Radiochemistry and Nuclear Chemistry, Institute of Nuclear Chemistry and Technology,

16 Dorodna Str., 03-195 Warsaw, Poland,

Tel.: +48 22504 1054, Fax: +48 22811 1917,

E-mail: m.rogowski@ichtj.waw.pl

Received: 18 June 2015

Accepted: 5 September 2015

\section{Introduction}

The development of the new reactors' generation - generation-IV fast-neutron reactors - points the way to new research. These systems offer significant progress in sustainability, safety and reliability, economics, proliferation resistance (depending on the perspective) and physical protection. Fast neutron nuclear reactors deployment requires the closure of the nuclear fuel cycle to optimize the consumption of natural resources (typically multiplying energy production up to 100 for the same quantity of uranium) and to minimize high-level wastes. The further R\&D activities focuses on the development of extraction methods for the uranium recovery from low grade raw materials, closed fuel cycle chemistry, mixed oxide fuels (MOX) manufacturing, but also for carbide and nitride fuel chemistry [1].

Carbide fuels have many advantages compared to currently used MOX fuels, e.g. several times higher thermal conductivity, high thermal resistance (no significant creep behavior up to $1000^{\circ} \mathrm{C}$ ), low neutron cross section, high density (UC approx. $13.6 \mathrm{~g} / \mathrm{cm}^{3}$ ), high resistance during irradiation to high burn-up and high corrosion resistance. These properties permit an increase in the operating parameters of the core. Moreover, carbon in the compound is easily handled in its subsequent chemical processing [2-5]. 
The production of uranium carbide fuels is a very difficult process. Uranium carbide is formed by direct reduction of uranium oxides with carbon in a carbothermic reaction under strict conditions (Eqs. (1), (2)). Moreover, uranium carbide can be obtained by reaction of metallic uranium with carbon or methane (Eqs. (3), (4)).

$$
\text { (4) } \mathrm{U}+\mathrm{CH}_{4} \rightarrow \mathrm{UC}+2 \mathrm{H}_{2}
$$$$
T=2100^{\circ} \mathrm{C}
$$

In this paper, an alternative method of uranium carbide synthesis is proposed. The powder-free complex sol-gel process (CSGP) for the synthesis of advanced ceramic materials has been applied. The CSGP process is an original variant of a sol-gel method, which it has been elaborated in the Institute of Nuclear Chemistry and Technology (Polish Patent [6]). The main aim of this method is to use ascorbic acid as a complexing agent to obtain stable aqueous sols with a high degree of amorphization and a homogenous distribution of the components. CSGP has been used to synthesize a variety of advanced ceramic materials e.g. high temperature conductors [7], hydroxyapatite [8], $\mathrm{Li}_{2} \mathrm{TiO}_{3}$ [9], uranium dioxide $[6,10-12]$, etc.

Ascorbic acid $\left(\mathrm{C}_{6} \mathrm{H}_{8} \mathrm{O}_{6}\right)$ is a well-known natural antioxidant and vitamin (vitamin C) which is widely distributed in nature. Structurally, ascorbic acid is a sugar, a $\gamma$-lactone, and enediol. It is unstable and is rapidly oxidized (according to Eq. (5)) to dehydroascorbic acid (DHA- $\mathrm{C}_{6} \mathrm{H}_{6} \mathrm{O}_{6}$ ) due to the presence of two hydroxyl groups in its structure. These oxidation reactions can be induced by increased temperatures, higher $\mathrm{pH}$, light, and presence of oxygen or various metals ions that have suitable redox potentials [13].

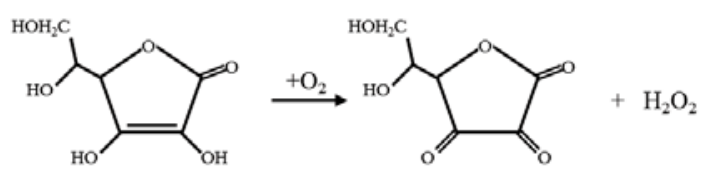

In the literature, it is possible to find examples of the use of ascorbic acid as a carbon source, e.g. in synthesis of $\mathrm{Li}_{3} \mathrm{~V}_{2}\left(\mathrm{PO}_{4}\right)_{3} / \mathrm{C}$ [14] and $\mathrm{Li}_{2} \mathrm{FeSiO}_{4} / \mathrm{C}$ [15] as cathode materials for lithium ion batteries or for the synthesis of carbon coated PbTe [16] and CdTe [17] nanowires. However, information about the application of ascorbic acid as a carbon source to synthesize carbide fuels is lacking in the literature.

Ascorbic acid has a single pair of electrons on oxygen of hydroxyl groups and it forms a coordination bond with a uranyl ion. The addition of the uranyl ion to ascorbic acid with a molar ratio of $1: 1$ produces brown complex $\left[\mathrm{UO}_{2} \mathrm{~A}\right]^{+}$, where $\mathrm{A}^{-}$is ascorbate monoanion $\left(\mathrm{C}_{6} \mathrm{H}_{7} \mathrm{O}_{6}\right)^{-}[18,19]$. The complex formation may be presented by reaction (Eq. (6)) .

(6) $m \mathrm{MeO}_{2}^{2+}+n \mathrm{HA} \leftrightarrows\left[\left(\mathrm{MeO}_{2}\right)_{m} \mathrm{~A}_{n}\right]^{2 m-n}+n \mathrm{H}^{+}$
Ascorbic acid is totally decomposed during thermal treatment conducted in air atmosphere in the CSGP. The authors propose to use ascorbic acid also as a carbon source for the synthesis of uranium carbide. The presented results focus on the first step of the thermal treatment - i.e. the carbonization process, which was carried out in the free-oxygen atmosphere to provide a mixture of carbon and uranium oxides. The $\mathrm{N}_{2}, \mathrm{Ar}$ atmospheres and vacuum atmospheres for decomposition of the uranyl-ascorbate complex to the mixture of uranium dioxide with carbon were investigated.

\section{Experiment}

\section{Materials}

The following reagents were used: uranium trioxide (The British Drug Mouse LTD, B.D.H. Laboratory Chemicals Division), ascorbic acid (ASC) (pharmaceutical grade, Takeda Europe GmBH). The purity of used analytical nitrogen and argon gaseous were $99.9999 \%$. The rest of the reagents were also used as analytical pure grade.

\section{Synthesis of uranyl-ascorbate gel}

Uranyl-ascorbate sols were prepared by the addition of uranium trioxide to a $1 \mathrm{M}$ ascorbic acid aqueous solution. The preparation of the homogenous solution of the sol with MR ASC/U = 1 is a key issue. The plain flowchart of uranyl-ascorbate gel production by the CSGP with subsequent steps of uranium carbide synthesis is shown in Fig. 1. More details about the CSGP and the IChTJ gelation method to obtain spherical particles are presented by Deptula [10] and Brykala [11].

The carbonization process, presented in Fig. 1 was carried out in a chamber furnace (Nabertherm VHT 08/18 GR, $8 \mathrm{dm}^{3}$ volume) in nitrogen and argon atmospheres at a flow rate of $150 \mathrm{~L} / \mathrm{h}$ and in vacuum $(0.05 \mathrm{mbar})$, as initial conditions. The uranyl-ascorbate gels with size of particles 50-100 $\mu \mathrm{m}$

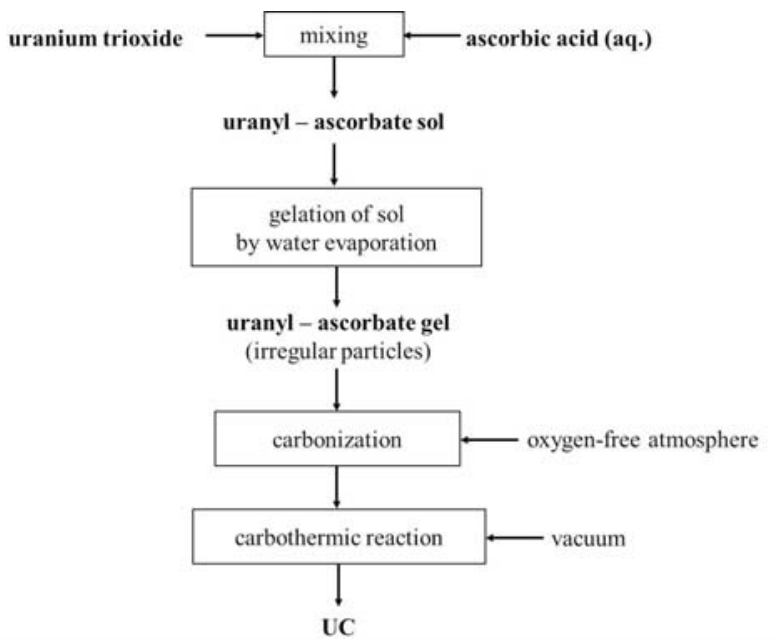

Fig. 1. Flowchart of uranium carbide preparation in the CSGP. 


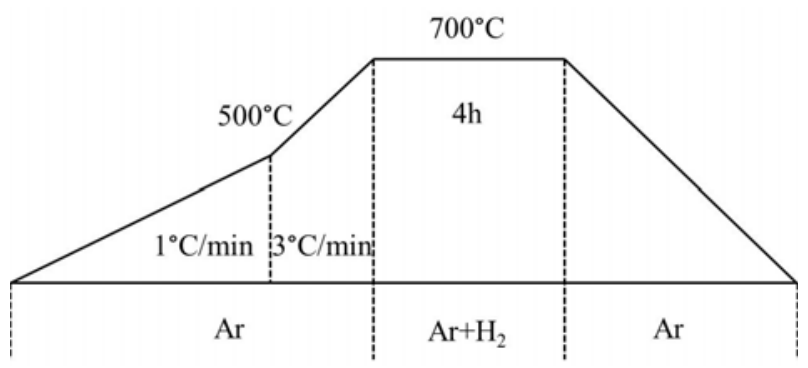

Fig. 2. Flowchart of carbonization process of uranyl-ascorbate gels.

were carbonized using the furnace program showed in Fig. 2. The conditions of the thermal treatment were determined on the basis of TG-DTG results in a nitrogen atmosphere.

\section{Sample characterization}

The thermal behavior of ascorbic acid and uranyl-ascorbate gel during the carbonization process in nitrogen was investigated by thermogravimetric analysis (TG-DTG - SDT Q600, TA Instruments). The samples were heated from $25^{\circ} \mathrm{C}$ to $900^{\circ} \mathrm{C}$ at a heating rate of $10^{\circ} \mathrm{C} \cdot \mathrm{min}^{-1}$. The experiments were carried out in a nitrogen atmosphere at the flow rate of $100 \mathrm{~mL} \cdot \mathrm{min}^{-1}$. The sample was placed in an alumina crucible while an empty alumina crucible of the same size was utilized as a reference. The carbon content was also calculated from the mass loss in air atmosphere $\left(700-900^{\circ} \mathrm{C}\right)$ from samples (with size 30-70 $\mu \mathrm{m}$ ) that were carbonized earlier in the inert atmosphere.

The characterization of the carbonization products was carried out using X-ray diffraction (XRD) on a Siemens D500 powder diffractometer equipped with a high-resolution semiconductor Si:Li detector using $K \alpha \mathrm{Cu}$ radiation $\lambda=1.5418 \AA$. The diffraction patterns were collected in a $\theta / 2 \theta$ scanning Bragg-Brentano mode, with a step of $0.05^{\circ}$, counting time of $4 \mathrm{~s} /$ step and in the $2 \theta$ range of $10^{\circ}-80^{\circ}$. The experimental data were analyzed using the XRAYAN phase analysis software and ICDD PDF4+ 2012 diffraction standards database.

\section{Results and discussion}

The TG-DTG plots of the behavior of ascorbic acid and uranyl-ascorbate gel in a nitrogen atmosphere are shown in Figs. 3 and 4.

The data obtained from the TG analysis of ascorbic acid (in nitrogen) show three main stages of decomposition. Solid ascorbic acid is stable up to ca. $180^{\circ} \mathrm{C}$, then it starts to decompose with the maximum rate of decomposition at $231^{\circ} \mathrm{C}$. The first stage of decomposition occurs at $180-260^{\circ} \mathrm{C}$ and the mass loss is $36.3 \%$ which is equivalent to the release of $\mathrm{H}_{2} \mathrm{O}$ and $\mathrm{CO}_{2}$, little $\mathrm{HCOOH}$ and $\mathrm{CO}$. At that moment the decarboxylation and dehydration process occurs. The second mass loss $-30.5 \%$ at $260-470^{\circ} \mathrm{C}$ of equivalent of $\mathrm{CO}_{2}$ and $\mathrm{CO}$ (decarboxylation and decarbonylation process). At the final stage of the decomposition of ascorbic acid at $470-800^{\circ} \mathrm{C}-$ a slow carbonization and slow mass loss is observed. At the third stage, $\mathrm{CO}$ and $\mathrm{CH}_{4}$ are released. The total mass loss is about $75 \%$ and the rest is the equivalent of carbon residue. It is known that the decomposition of ascorbic acid is very complex and over 200 different products of the degradation have been reported [20-24].

The TG-DTG analysis of uranyl-ascorbate gel in nitrogen (Fig. 4) shows the three maxima. The gel is stable to ca. $130^{\circ} \mathrm{C}$, because the mass loss before $100^{\circ} \mathrm{C}$ is connected to the gel drying. The maximum rate of the decomposition for first maximum occurs at ca. $160^{\circ} \mathrm{C}$ and represents the release of ca. $19.5 \%$ i.e. molecular $\mathrm{H}_{2} \mathrm{O}$ and $\mathrm{CO}_{2}$. The second mass loss $-10 \%$ at $180-270^{\circ} \mathrm{C}$, is equivalent to $\mathrm{CO}_{2}$ and $\mathrm{CO}$. During the last maximum of the decomposition of uranyl-ascorbate gel at $270-490^{\circ} \mathrm{C} \mathrm{CO}_{2}$ and $\mathrm{CO}$ are still released, but additionally a homogenous mixture of uranium oxides with carbon is formed. The slow carbonization and slow mass loss is observed above $490^{\circ} \mathrm{C}$. The total mass loss in nitrogen is about $49 \%$.

The results of the ascorbic acid decomposition are crucial to calculate ASC quantity which should be used to obtain the desired quantity of carbon. The calculation is based on the experimental analysis. An amount of $15.2 \pm 0.1 \mathrm{mmol} \mathrm{C}$ have been obtained from $4.0 \mathrm{mmol}$ ASC, therefore generally

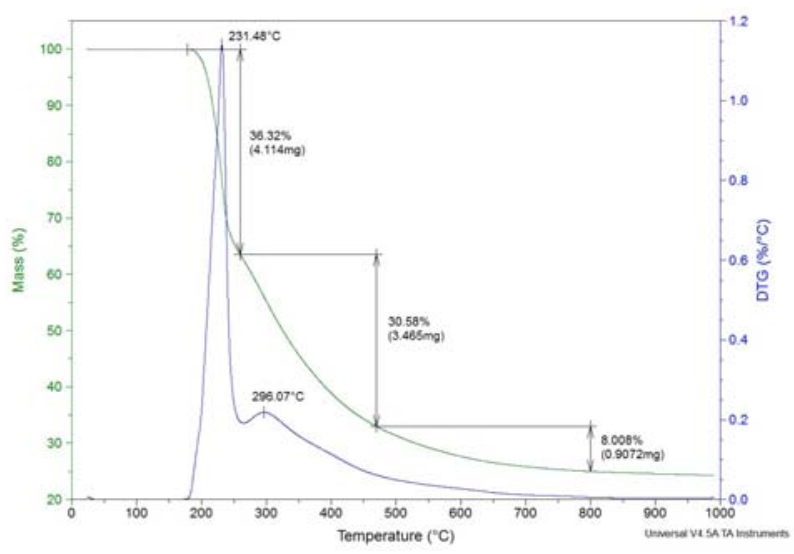

Fig. 3. Thermogravimetric curves of ascorbic acid $(11.3280 \mathrm{mg})$ annealed in nitrogen (heating rate: $10^{\circ} \mathrm{C} \cdot \mathrm{min}^{-1}$, gas flow: $\left.100 \mathrm{~mL} \cdot \mathrm{min}^{-1}\right)$.

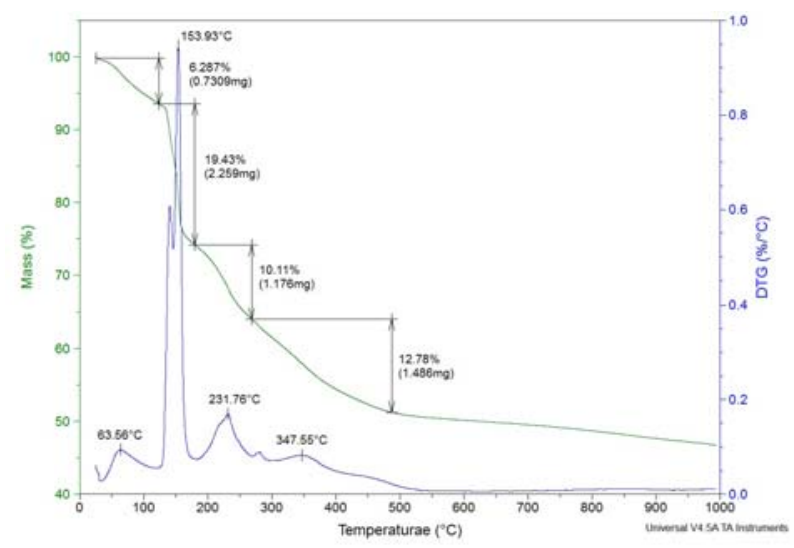

Fig. 4. Thermogravimetric curves of uranyl-ascorbate gel (MR ASC/U = 1, $11.6260 \mathrm{mg}$ ) annealed in nitrogen (heating rate: $10^{\circ} \mathrm{C} \cdot \mathrm{min}^{-1}$, gas flow: $100 \mathrm{~mL} \cdot \mathrm{min}^{-1}$ ). 


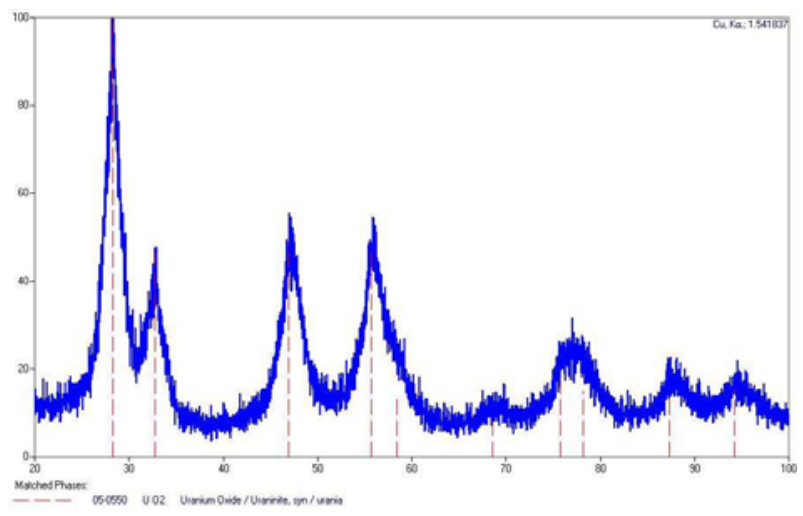

Fig. 5. XRD pattern of the carbonized uranyl-ascorbate gel in argon atmosphere.

whole synthesis (with carbonization and carbothermic reduction) can be presented by Eqs. (7) and (8). Carbothermic reduction requires an adequate $\mathrm{C}: \mathrm{UO}_{2}$ molar ratio. In order to synthesize $\mathrm{UC}, \mathrm{C}: \mathrm{UO}_{2}$ molar ratio $3: 1$ is needed.

$$
\mathrm{UO}_{3}-\mathrm{ASC} \underset{\Delta T, \mathrm{Ar} \text { or vacuum }}{\stackrel{\Delta T, \mathrm{Ar}}{\longrightarrow} \mathrm{UC}} \mathrm{UO}_{3}-\mathrm{C} \stackrel{\Delta T, \mathrm{Ar}+\mathrm{H}_{2}-\mathrm{H}_{2} \mathrm{O}}{\longrightarrow} \mathrm{UO}_{2}-\mathrm{C}
$$

(8) $8.7 \mathrm{mmol} \mathrm{ASC}+10 \mathrm{mmol} \mathrm{UO}_{3} \rightarrow 10 \mathrm{mmol} \mathrm{UC}$ $+20 \mathrm{mmol} \mathrm{CO}\left(+\mathrm{CH}_{4}, \mathrm{H}_{2}\right)$

The X-ray diffraction patterns of the carbonized samples of uranyl-ascorbate gel in nitrogen, argon and vacuum atmospheres confirmed that the main products are $\mathrm{UO}_{2}$ and carbon. Carbon does not appear in the XRD, which may indicate its amorphous form. XRD patterns for all samples look very similar to this in Fig. 5. The unspecified form of carbon or graphite which is present in samples will be the carbon source for carbothermic reduction.

In order to analyze the carbon content in the samples after the carbonization of uranyl-ascorbate gel in different oxygen-free atmospheres, the specific TG analysis was performed. The samples were heated in nitrogen from $25^{\circ} \mathrm{C}$ to $700^{\circ} \mathrm{C}$ and then the atmosphere changed to air and was heated to $900^{\circ} \mathrm{C}$. The samples were annealed with a heating rate of $20^{\circ} \mathrm{C} \cdot \mathrm{min}^{-1}$ and at a flow rate of gases $100 \mathrm{~mL} \cdot \mathrm{min}^{-1}$. It was possible to calculate the amount of carbon from the difference of mass loss between $700-900^{\circ} \mathrm{C}$. TG curves for the carbonized samples of $\mathrm{UO}_{2}-\mathrm{C}$ treated in nitrogen $(20.3240 \mathrm{mg}$, green line), in argon (26.9340 mg, red line) and in vacuum (20.4940 mg, black line) are presented in Fig. 6 .

The results of the TG analysis for all of the carbonized samples (Fig. 6) show that the mass loss in the temperature $700-900^{\circ} \mathrm{C}$ in air is (respectively) $16.55,11.02$ and $17.61 \%$, which is an equivalent

Table 1. Calculation of molar ratio U/C

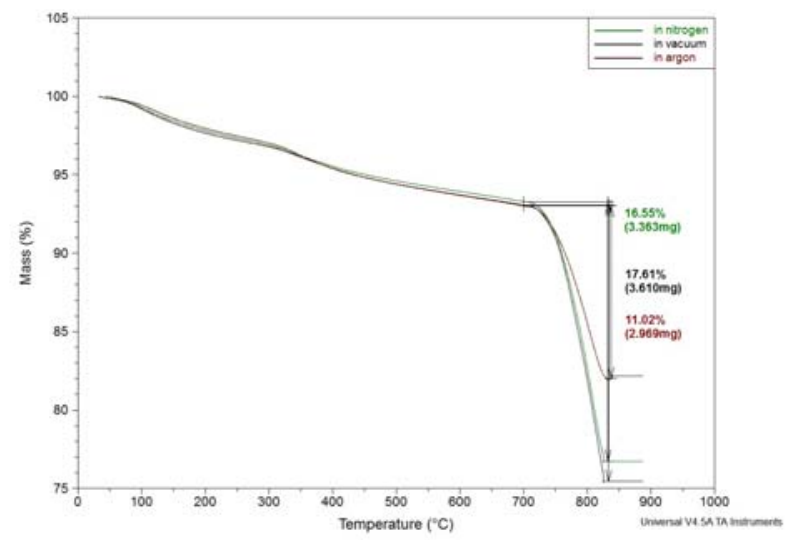

Fig. 6. Carbon TG analysis of the $\mathrm{UO}_{2}-\mathrm{C}$ samples carbonized in various atmospheres (heating rate: $10^{\circ} \mathrm{C} \cdot \mathrm{min}^{-1}$, gas flow: $100 \mathrm{~mL} \cdot \mathrm{min}^{-1}$ ).

to the amount of carbon after this step. In Table 1 calculations of molar ratio $\mathrm{U} / \mathrm{C}$ based on the mass loss (Fig. 6) are presented.

The preliminary calculations show that the molar ratio of $U$ to $C$ in the samples after the carbonization is $1: 4.6\left(\mathrm{~N}_{2}\right), 1: 3.1$ (Ar) and $1: 5$ (vacuum). That means that the output amount of ASC in uranyl-ascorbate gel with MR ASC/U = 1 was sufficient to obtain an adequate amount of carbon. Therefore, it is necessary to decrease the amount of ascorbic acid in uranyl-ascorbate gel because a higher amount of carbon (than $\mathrm{U} / \mathrm{C}=1: 3$ ) in the mixture with $\mathrm{UO}_{2}$ favors the formation of $\mathrm{UC}_{2}$ during a carbothermic reduction. Nevertheless, under these conditions of treatment, especially Ar provides the ratio U/C equal $1: 3$, which is necessary to synthesis of homogeneous UC. Other atmospheres $\left(\mathrm{N}_{2}\right.$ and vacuum) provide higher molar ratios, what enforces decrease of starting molar ratio ASC/U.

\section{Conclusion}

The results of study show that various oxygen-free atmospheres for the carbonization process are very important, because they control the amount of formed carbon. The thermal behavior during the carbonization process of uranyl-ascorbate gel and ascorbic acid in nitrogen were similar: ascorbic acid begins to decompose at $180^{\circ} \mathrm{C}$ and solid uranyl-ascorbate gel at $130^{\circ} \mathrm{C}$. In both cases, $\mathrm{H}_{2} \mathrm{O}, \mathrm{CO}_{2}$, $\mathrm{CO}, \mathrm{HCOOH}$ and $\mathrm{CH}_{4}$ were released during the decomposition process. Additionally, in the case of the carbonization of gel, formation of a homogenous mixture of uranium oxides with carbon residue at $T=310-510^{\circ} \mathrm{C}$ was observed. The amount of carbon residues depends on the protective atmospheres and was as high as $-16.55 \%$ (in $\mathrm{N}_{2}$ ), $11.00 \%$ (in $\mathrm{Ar}$ ) and $17.62 \%$ (in vacuum), so that the molar ratio

\begin{tabular}{lccc}
\hline Carbonization atmosphere & $\begin{array}{c}\text { Mass loss } \\
{[\mathrm{mg}]}\end{array}$ & $\begin{array}{c}\text { Carbon amount } \\
{[\mathrm{mmol}]}\end{array}$ & $\begin{array}{c}\text { Uranium amount } \\
\left.[\mathrm{mmol}]^{*}\right)\end{array}$ \\
\hline $\mathrm{N}_{2}$ & 3.363 & 0.28 & 0.06 \\
$\mathrm{Ar}$ & 2.969 & 0.25 & 0.08 \\
Vacuum & 3.610 & 0.30 & 0.06 \\
\hline
\end{tabular}

") Calculations based on the assumption that $\mathrm{UO}_{2.67}$ is the only residue. 
of $\mathrm{U}$ to $\mathrm{C}$ in the samples after the process is $1: 4.6$ $\left(\mathrm{N}_{2}\right), 1: 3.1$ (Ar) and 1:5 (vacuum). It means that the yield from ASC is sufficient to obtain adequate amounts of carbon which acts as a reactant in the carbothermic reduction. It is therefore necessary to decrease the amount of ascorbic acid in uranyl-ascorbate gel because a higher amount of carbon in the mixture with $\mathrm{UO}_{2}$ favors the formation of $\mathrm{UC}_{2}$ during carbothermic reduction. Nevertheless, under these conditions Ar provide the $3: 1$ ratio $\mathrm{C}: \mathrm{U}$, which is necessary to synthesis of UC.

The idea to apply the powder-free CSGP with ascorbic acid as a complexing agent and as a carbon source to synthesize uranium carbide shortens the time of the solid state reaction, eliminates work with incorporation of dusty carbon black and improves the homogenous distribution of carbon in the whole volume of the samples.

Acknowledgments. The work was carried out within the collaborative Project ASGARD (Advanced Fuels for Generation IV Reactors: Reprocessing and Dissolution), ECGA no. 295825 FP7-FISSION-2011.

\section{References}

1. Chmielewski, A. G. (2008). Nuclear fissile fuels worldwide reserves. Nukleonika, 53(Suppl. 2), S11-S14.

2. Phillips, J. A., Nagley, S. G., \& Shaber, E. L. (2012). Fabrication of uranium oxycarbide kernels and compacts for HTR fuel. Nucl. Eng. Des., 251, 261-281.

3. Knight, T. W., \& Anghaie, S. (2002). Processing and fabrication of mixed uranium/refractory metal carbide fuels with liquid-phase sintering. J. Nucl. Mater., 306, 54-60.

4. Sahoo, B. D., Joshi, K. D., \& Gupta, S. C. (2013). Ab initio study on structural stability of uranium carbide. J. Nucl. Mater., 437, 81-86.

5. Zverev, D. V., Kirillov, S. N., Dvoeglazov, K. N., Shadrin, A. Y., Logunov, M. V., Mashkin, A. N., Schmidt, O. V., \& Arseenkov, L. V. (2012). Possible options for uranium-carbide SNF processing. Procedia Chem., 7, 116-122.

6. Deptula, A., Brykala, M., Lada, W., Wawszczak, D., Olczak, T., \& Chmielewski, A. G. (2014). Polish Patent PL 219069. Warsaw, Polish Patent Office.

7. Deptula, A., Lada, W., Olczak, T., Lanagan, M. T., Dorris, S. E., Goretta, K. C., \& Poeppel, R. B. (1997). Polish Patent No. 172618. Warsaw, Polish Patent Office.

8. Deptula, A., Lada, W., Olczak, T., Borello, A., Alvani, C., \& Di Bartolomeo, A. (1992). Preparation of spherical powders of hydroxyapatite by sol-gel process. $J$. Non-Cryst. Solids, 147/148, 537-541.

9. Deptula, A., Brykala, M., Lada, W., Olczak, T., Sartowska, B., \& Chmielewski, A. G. (2009). Preparation of spherical particles of $\mathrm{Li}_{2} \mathrm{TiO}_{3}$ (with diameters below $100 \mu \mathrm{m})$ by sol-gel process. Fusion Eng. Des., $84,681-684$.
10. Deptula, A., Brykala, M., Lada, W., Olczak, T., Wawszczak, D., Modolo, G., Daniels, H., \& Chmielewski, A. G. (2010). Synthesis of uranium dioxides by complex sol-gel processes (CSGP). In Proceedings of the 3rd International Conference on Uranium, 40th Annual Hydrometallurgy Meeting (Vol. II, pp. 145-154). Saskatoon, Saskatchewan, Canada.

11. Brykala, M., Deptula, A., Rogowski, M., Lada, W., Olczak, T., Wawszczak, D., Smolinski, T., Wojtowicz, P., \& Modolo, G. (2014). Synthesis of microspheres of triuranium octaoxide by simultaneous water and nitrate extraction from ascorbate-uranyl sols. $J$. $\mathrm{Ra}$ dioanal. Nucl. Chem., 299, 651-655.

12. Chmielewski, A. G. (2011). Chemistry for the nuclear energy of the future. Nukleonika, 56(3), 241-249.

13. Novakova, L., Solich, P., \& Solichova, D. (2008). HPLC methods for simultaneous determination of ascorbic and dehydroascorbic acids. Trends Anal. Chem., 27, 942-958.

14. Huang, J. S., Yang, L., \& Liu, K. Y. (2011). One-pot syntheses of $\mathrm{Li}_{3} \mathrm{~V}_{2}\left(\mathrm{PO}_{4}\right)_{3} / \mathrm{C}$ cathode material for lithium ion batteries via ascorbic acid reduction approach. Mater. Chem. Phys., 128, 470-474.

15. Yan, Z., Cai, S., Miao, L., Zhou, X., \& Zhao, Y. (2012). Synthesis and characterization of in situ carbon-coated $\mathrm{Li}_{2} \mathrm{FeSiO}_{4}$ cathode materials for lithium ion battery. J. Alloys Compd., 511, 101-106.

16. Yong, S. M., Muralidharan, P., Kim, D. S., \& Kim, D. K. (2011). One-step hydrothermal synthesis of carbon-coated $\mathrm{PbTe}$ nanowires for thermoelectric applications. Rev. Adv. Mater. Sci., 28, 13-16.

17. Yong, S. M., Muralidharan, P., Jo, S. H., \& Kim, D. K. (2010). One-step hydrothermal synthesis of CdTe nanowires with amorphous carbon sheaths. Mater. Lett., 64, 1551-1554.

18. Gregorczyk, Z. (1958). Determination of coordination numbers of complexes formed by ascorbic acid with uranyl or titanyl ions. Acta. Pol. Pharm., 15, 129-140.

19. Sobkowska, A., \& Minczewski, J. (1961). Potentiometric investigation of the system $\mathrm{UO}_{2}{ }^{2+}$-ascorbic acid. Roczniki Chemiczne, 35, 47-58.

20. Jingyan, S., Yuwen, L., Zhiyong, W., \& Cunxin, W. (2013). Investigation of thermal decomposition of ascorbic acid by TG-FTIR and thermal kinetics analysis. J. Pharm. Biomed. Anal., 77, 116-119.

21. Shephard, A. B., Nichols, S. C., \& Braithwaite, A. (1999). Moisture induced solid phase degradation of L-ascorbic acid part 3: structural characterization of the degradation products. Talanta, 48, 607-622.

22. Juhász, M., Kitahara, Y., \& Fujii, T. (2011). Thermal decomposition of vitamin C: an evolved gas analysis-ion attachment mass spectrometry study. Food Chem., 129, 546-550.

23. Vernin, G., Chakib, S., Rogacheva, S. M., Obretenov, T. D., \& Parkanyi, C. (1998). Thermal decomposition of ascorbic acid. Carbohydr. Res., 305, 1-15.

24. Juhász, M., Kitahara, Y., Takahashi, S., \& Fujii, T. (2012). Thermal stability of vitamin C: thermogravimetric analysis and use of total ion monitoring chromatograms. J. Pharm. Biomed. Anal., 59, 190-193. 